Rupkatha Journal on Interdisciplinary Studies in Humanities (ISSN 0975-2935), Vol. 10, No. 1, 2018 Special Issue on "Interrogating Cultural Translation: Literature and Fine Arts in Translation and Adaptation" In collaboration with the Department of English, Amrita Vishwa Vidyapeetham Guest-edited by Dr. Hari M G, Amrita Vishwa Vidyapeetham, Coimbatore, India DOI: https://dx.doi.org/10.21659/rupkatha.v10n1.18 Full Text: http://rupkatha.com/V10/n1/v10n118.pdf

\title{
Negotiating Identity in a Multi-cultural Context in Elizabeth Wong's Kimchee and Chitlins: A Serious Comedy about Getting Along
}

\author{
Hana' Khalief Ghani \\ College of Arts/Department of Translation, Al-Mustansiriyah University. \\ Email: h.horizons2013@gmail.com
}

Received November 20, 2017; Revised January 28, 2018; Accepted February 14, 2018; Published February $25,2018$.

\begin{abstract}
Based on the real story of the racial clash that took place between two hyphenated minorities in the United States of America, namely; the Korean and the African in Los Angeles in 1990, this paper sets out to explore issues that go beyond this apparently simple racial conflict. Kimchee and Chitlins, indeed, is a serious attempt by the Chinese-American dramatist Elizabeth Wong, being herself a journalist and a member of minority community, to dig deep into the problems that plague and are still plaguing these communities, namely; racial discrimination and profiling, stereotyping and marginalization, and loss of cultural heritage. Drawing on the theories of 'Melting Pot' and 'Salad Bowl', the paper discusses the politics of identity in relation to the main characters' attempt to define 'who are they' and 'how do they look at themselves as well as at others in their multicultural society.' To overcome these problems, the dramatist encourages members of minorities to reach out to each other and understand the cultural as well as other types of differences that do separate them. Rather than yielding to, and assimilating into the main society, Wong advocates preserving the cultural heritage besides developing the skills of coexisting and tolerating the Other. The title of the play is a clear reference to Wong's suggestion as 'Kimchee' is the 'heart of Korea'-its most popular meal- and 'Chitlins' is a translation of the 'history' of African people in America. Putting them beside each other certainly means the possibility of coexistence and mutual understanding and respect.
\end{abstract}

Keywords: Wong, Kimchee and Chitlins, minorities, Koreans, Afro-Americans, (anti)assimilation, coexistence, cultural differences.

\section{Immigration, Identity, and Multiculturalism}

Leaving homeland and immigrating to another country does not mean physical displacement only, it also means psychological, social, and cultural displacement. The immigrants in their host societies are often introduced to a completely new set of values, ideas, life styles, and social and cultural norms. This results in a 'crisis of identity'; a common experience which almost all the immigrants share. Kobena Mercer discusses the pivotal place 'identity' occupies in the life of immigrants. He eloquently remarks: 
Just now everybody wants to talk about 'identity.' As a keyword in contemporary politics it has taken on so many different connotations that sometimes it is obvious that people are not even talking about the same thing. One thing at least is clear - identity only becomes an issue when it is in crisis, when something assumed to be fixed, coherent and stable is displaced by the experience of doubt and uncertainty.(qtd in Heike Berner, 2003, p.10)

In the age of globalization, trans-nationalization, wars, economic and political instability, "in the age of the refugee, dislocated persons, mass immigration,"(Edward Said in Ferguson et al, 1990, p.375) identity - with all its different connotations - has become an inescapable issue. The cause for the many different connotations mentioned by Mercer lies in the very nature of identity: similar to race and ethnicity, identity is a construct(Michael Omi and Howard Winant, 1986, p.7o). The identity of a person consists of various aspects, fixed and shifting, self-assigned and assigned by others. Thus, it can vary depending on the time, the point of view, and the physical and intellectual location of the defining/defined person(Heike Berner, 2003, p.10).

This crisis of identity is made worse by a number of structural, institutional, and legal regulations and procedures that contribute to 'otherizing' and 'inferiorizing' the immigrants by the dominant society. The immigrants usually have to choose among three main options in their new host societies: either to assimilate into the main stream society and forsake the original identity mainly by adopting the social, cultural, and behavioral norms of the host society; to refuse to assimilate and to reject the norms and values of the host society, and consequently sticking to the norms of their original societies; or try to find a new, third and more balanced identity that enables them to preserve their old identities and adjust to the new ones as well.

More often than not, the 'crisis of identity' becomes more acute in multicultural societies like the United States of America, the locale of Wong's play. It is well-known that "the growth of African American, Hispanic, Asian, and American Indian populations" has played a major role in rapidly changing the demographics of the American society and "diversify[ing] the racial and ethnic makeup of schools, workplaces and neighborhoods"(Olson, 2003, p.1). According to Sarah Song (2017) the idea of multiculturalism in contemporary political discourse and in political philosophy is about how to understand and respond to the challenges associated with cultural and religious diversity. The term "multicultural" is often used as a descriptive term to characterize the fact of diversity in a society. While the term has come to encompass a variety of prescriptive claims, it is fair to say that proponents of multiculturalism reject the ideal of the "melting pot" in which members of minority groups are expected to assimilate into the dominant culture in favor of an ideal in which members of minority groups can maintain their distinctive collective identities and practices. In the case of immigrants, proponents of 'multiculturalism' emphasize that it is compatible with, not opposed to, the integration of immigrants into society; multiculturalism policies provide fairer terms of integration for immigrants. Furthermore, Glazer (1997), Hollinger (1995), and Taylor (1992) point out that 'Multiculturalism' has often been used as an umbrella term to characterize the moral and political claims of a wide range of marginalized groups, including African Americans, women, LGBT people, and people with disabilities.

No doubt, the individuals who come from all over the world to settle in America, bring with them different cultures, values, religions, and languages that interact with, and change, the communities in which they live. As America continues to diversify, those individuals must be taught how to interact with others who may be different from them. It has become the society's responsibility to teach both minority and non-minority people the necessary social skills they need to function in the ever-changing world. Unfortunately, American society usually focuses on 
Eurocentric ways of communicating, understanding, and interpreting the past and the present((Hughes, 1996/1997 in Olson, 2003, p.6).

Consequently, multiculturalism is closely associated with "identity politics," "the politics of difference," and "the politics of recognition and representation," all of which share a commitment to revaluing underappreciated and underrepresented identities and changing dominant patterns of representation and communication that marginalize certain groups. More important, multiculturalism involves not only claims of identity and culture as some of its critics suggest. It is also a matter of economic interests and political power: it includes demands for remedying economic and political disadvantages that some people in America suffer as a result of their marginalized group identities(Gutmann 2003, Taylor 1992, Young 1990 in Song, 2017).

Historically, the presence of Africans and Asians dates back to the $17^{\text {th }}$ and $18^{\text {th }}$ centuries respectively. However, this presence, in spite of its importance in defining America as a country in the past and the present, has often been tarnished by racial discrimination, misunderstanding, exploitation and exclusion. The International Convention on the Elimination of all Forms of Racial Discrimination defines Racism as

any distinction, exclusion, restriction, or preference based on race, color, descent or national or ethnic origin which has the purpose of nullifying or impairing the recognition, enjoyment or exercise, on equal footing, of human rights and fundamental freedoms in the political, economic, social, cultural or any other field of public life. (qtd. in Marco Fugazza, 507)

In America and throughout the world, the idea of 'race' is inescapably knotted with visible markers such as hair and skin color and facial expressions. Color- 'black' and 'yellow' in Wong's Kimchee and Chitlins, stands in metonymic relation to a vast complex of stories, images, mythologies, emotions, scientific discourses and genomic sequences of what we know and define as race (Carolyn Erler 1).

In relation to racism, White domination in America is often rationalized by the belief that the inferiority or superiority of a group's abilities, values, and culture, is linked to physical characteristics such as skin color (Feagin and Sikes,1994, 4). Derald Wing Sue (2003, p.30) points out the danger of such a viewpoint. He asserts that judging the blacks or Asians as different, and therefore, inferior because of their color and physical characteristics encourages the whitedominated society to systematically subordinate them to their own values and perspectives. Accordingly, racism is "a systemic exercise of real power to deny minorities equal access and opportunity, while maintaining the benefits and advantages of white American". The subordination of persons of color, i.e., Black and Asians, in the United States, Sue adds, occurs not just on the individual level but also in the activities and procedures of the American institutions, corporations, and social systems (Ibid., 31).

Thus racism denotes prejudice, oppression, and atrocities against Afro-and Asian-Americans who formed a significant part of population yet subjected to tremendous discrimination(Racism against African Americans). In "Five Faces of Oppression," Iris Marion Young(in Heldke \& O'Connor, 2004, p.1) distinguishes five faces of oppression practices against Afro-American people, men and women alike. They are the faces of exploitation, marginalization, cultural imperialism, violence, and powerlessness. These faces, more often than not, lead to repetitive cycles of racial tensions, disempowerments, and mutual distrust (see Holzleithner in Janet Cormack, 2003). 
Moreover, both minorities suffer from what is now commonly known as "(Mis)representation." According to Stuart Hall, representation is "(T)he production of the meaning of the concepts in our minds through language." Representation then, in this context, refers to words or images that stand for social groups and categories. Creating and controlling the image for specific purposes constitute the "politics of representation"(In Coleman, 2003, p.24). This "politics of representation" complicates the ways the Blacks/Asians are presented on the stage. Not only is the politics of representation concerned with the creation and control of the image, but also with whether the image that is created is accurate or empowering. Unfortunately, the images of Black/Asians were far from being accurate or empowering. The Blacks, for example, were usually presented as fools, violent, ignorant, grinning, happy-go lucky, dandified coon, and subservient(Coleman, 2003, p.30).

Similar to their position in public life, the Blacks on the American stage have been "subordinated, marginalized, positioned, and devalued in every possible manner to glorify and relentlessly hold in place the white-dominated symbolic order and racial hierarchy of American society"(Ed Guerrero, in Coleman, 2003, p.26).

The same is true of the representation of the Asians in public life and on stage, The stereotype which the Asians were most distressed about, is the image of emasculated Asian American male: "The white stereotype of the acceptable and unacceptable Asian is utterly without manhood. At worst, the Asian American is contemptible because he is womanly, effeminate, devoid of all the traditionally masculine qualities of originality, daring, physical courage, and creating" (Chin 1991, 14-15).

Similar to the Blacks, the attempts of Asian-American to lead a normal life in America are hindered-from the early stages of their arrival- by a number of anti-Asian regulations and laws such as the Naturalization Act of 1790, the Page Law of 1875, the Chinese Exclusion Law 1882, the Alien Land Law in 1913 and the War Brides Act 1945 (see The Journey from Gold Mountain, 2006)

Asian Americans, generally, have been suffering from media invisibility, but when they are portrayed in television and movies, negative stereotypes abound. They are: "organized criminals, gang members, or inscrutable and mysterious "Orientals." Positive and balanced images of Asian Americans have increased over time, but they remain the "exception rather than the rule" (Ancheta, in Mai Fathy,p.95). The distorted images of Asian Americans in the American media came as a result of two phenomena: "the invisibility of Asians in general and the limited stereotypical roles offered to Asian American actors on screen". An Asian male is often portrayed as a "villain, gangster, dope peddler, or a weakling in distress. An Asian American woman is often seen as available and easy, or as the lotus blossom (a' la Madame Butterfly): an accessible and willing mistress to white man." The mainstream media reflect the interests of the majority of the audiences. This invisibility is a result of the "absence of strong Asian American film, television, and theatre in cultural arenas"(Joann Faung Jean Lee, 2000, 1).

Wong's Kimchee and Chitlins discusses these issues and develop them further to point out how deep-rooted they are in the daily life of minorities in America. Wong explicitly states the dangers of internalizing the patterns of racial bias and prejudice by the members of minority groups who, whether consciously or unconsciously, repeat these patterns in their interrelationships.

In this play, Wong explores the tense social relationships and cultural misunderstandings that resulted in the 1990 boycott of Korean greengrocers by Black community in Brooklyn, New York. The importance of Kimchee and Chitlins is that it has predicted the Los Angeles riots that took place in 1992 between African Americans and Korean Americans and extended to include all 
Asian Americans. It has shown how media misuse could affect the public badly by making irritation among ethnic groups, and how cultural misunderstandings and ignorance had helped intensify conflicts among them. The play has also explored how an Asian American playwright regards entertainment and news media and their role in forming Asian American image in the eyes of the American audience(Mai Fathy, 2003, p.v).

The lengthy 1990 boycott of the Family Red Apple Grocery in New York City and the 1992 Los Angeles riots have come to exemplify the so-called Black-Korean conflict of the late 1980s and early 1990 in the United States. The numerous accounts of antagonistic relations between black customers and Korean American merchants in inner-city neighborhoods that circulated during and after these events evinced a recurrent interest in the role that the daily conduct of store owners and employees may have played a role in aggravating the communities in which they ran their businesses. Focusing on ostensibly trivial behaviors such as making eye contact and giving change, media depictions of these tensions tended to assume and perpetuate notions of a fundamental "culture clash" between African Americans and recent Korean immigrants. Offering a pointed rejoinder to mainstream media accounts of the 1990 boycott, Wong's play tests, instead, the possibilities of cross-racial performance for representing and reconciling, and thus doubly "mediating," these disputes. Exploring the implications of assuming the gestures, mannerisms, and speech of those positioned as 'Other', the play grapples with the risks and limitations of such re-enactments, even as it imagines that traversing racial boundaries and mixing theatrical and journalistic conventions might elucidate the complex entanglements of habitual behaviors and habituated perceptions that inform both interracial tensions and their public narration(Jo Yun Kim, 2010).

\section{Identity, Food, and Co-existence in Wong's Kimchee and Chitlins}

Wong's Kimchee and Chitlins: A Serious Comedy about Getting Along (henceforth Kimchee and Chiltlins), opens with the ambitious journalist and correspondent, Suzie Seeto, who is modelled on Wong herself. After finishing her study in journalism at the University of Southern California in 1980, Wong worked as a reporter and a journalist with a number of newspaper and T.V. channels where she specialized in reporting and writing about minorities, in general, and AsianAmericans, in particular.

The first time the audience see Seeto, she was looking "longingly at the anchor chair"(Wong, 1996, p.5). In her desire to move upward socially, Seeto wants to be promoted to "take her seat in the anchor chair", but she cannot because of the many institutional barriers prevalent in the work places. One of these barriers is related to ethnicity. Seeto is not white; she is 'yellow.'

Before the boycott incident, Seeto was serious in her attempts to integrate in the dominant white society. Her boss's, Mark Thompson, opinion of her stresses this aspect. He declares: "Naturally, I like Suzie. But there's nothing exotic, nothing Asian about her"(p.34).

This draws attention to the representation of Asians in the American society which is based on stereotypical images and misconceptions of them as mysterious, exotic and primitive. This may explain why Seeto, in spite of her love of her job in general, "hates covering minority issues"(p.340). To her dissatisfaction, she is always assigned to cover only one kind of stories; i.e., the stories of "Asians, Latinos, Blacks, Jews, women,"(p.9) etc. Seeto believes that covering these issues will not avail her professionally. She wants to distance herself from her original community and not to be identified with its members. 
Seeto's latest experience of covering the racial riots that broke out in Brooklyn, New Work, was an eye opening and life-changing experience. It helps her reconsider her position in relation to minorities as well as the dominating white society. She describes this experience as 'hellish' and 'daunting'. She tells Thompson: "compared to where I've been, Dante's trip to purgatory was a joyride"(p.9). What was thought as a very ordinary task; i.e., covering and reporting the developments of the New Way Grocery Stores incident becomes a turning point in Seeto's personal and professional life. It helps her to redefine who she is? and how she wants to look like.

While reporting to the newsroom, Seeto becomes face to face with one of the factors that causes racial tension, i.e., language. This is crystal clear in some of the characters' demand to "speak English", as if they can not communicate unless resorting to a third language, neither Korean nor African. Using the language of the dominant group and relying exclusively on it in work places and other daily contexts may lead some members of minorities to give up their original languages and to adopt the language of their host societies.

There is another important aspect in relation to language that may result in confusion and misunderstanding. Black and white people alike tend to treat the Asians as if they are one group, and the same is true of how the Asians look at the Black people. That is obviously wrong as Wong's play elucidates. When Seeto says "Oh, it's wonga!"(p.8) in her description of what has been going in the store, neither Thompson, Tara Sullivan, the television anchor, the Korean Chorus nor the African Chorus understand the meaning of the word. So, Seeto explains to them: "It's Haitian. You know, voodoo," and then "(Aside.) I learned a few things on my last vacation"(p.8). Sometimes, people who live in the same place and belong to different linguistic groups need translation in their daily exchanges. Again, no one understands Grocer Mark when he asks: "E-guh-mua-ya?", which means "What is this?' to which Seeto replies: "I wish I spoke Korean"(p.10). Being Asian does not mean speaking the same language as this example illustrates.

Wong ingeniously chooses the chorus technique to express the theme of cultural clash between the two minorities; the Korean and the Black. The members of the chorus serve many functions: they are characters, reporters, and commentators. They also serve the purpose of defending the view point of each group, which is, regrettably, often biased and based on misconceptions. This may justify the initial attitude of the Black chorus and the Nurse Ruth Betty towards Seeto whom they reject believing she is Korean although she is not: she is Chinese. They want an AfroAmerican reporter because they think that a 'Korean girl' will not be objective in her covering of the 'boycotting' incident. They take for granted that she will take sides with her local community.

The relationship between the two minorities is obviously dominated by distrust, misunderstanding and stereotypical images. Racial epithet, descriptions and appellations are widely used by the two conflicting parties. Thus, the Koreans are 'yellow', 'coward', 'garbage', 'filthy', 'monkey.' Reverend Carter is the most extreme and the most outspoken among the Black community in his rejection of the Koreans as 'Others', and his insistence that they "should go back to Korea"(p.16). He believes that the only solution to the current tension is that "the Korean should leave the black community en masse. Who asked them to come? Go back to Korea"(p.19). In fact, he is a diehard adversary of the 'Other' whoever he is and in whatever shape it takes. This attitude is crystal clear in his sensitivity towards colors. He objects that there is "Too much white space" in the protest signs and asks one of the organizers to "Fill up that white space, with some black letters[!]"(p.27).

The Black Chorus voices the same sentiment when they ask their community to keep boycotting the Korean grocery shops and the protesters to keep "shouting anti-Korean slogans". They would rather let the shops commodities 'rot' than try to set things right. The situation was so tense and 
straining that it "looks like there's a curse on the street.... A curse on the whole fucking world"(p.18). It should be noted that, historically, the Blacks precede the Koreans in settling in the city. Seeto finds herself in front of a "sea of black faces" as more than fifty black protesters congregate against few Koreans. This implies two things. First, it may justify Reverend Carter's claim that the Koreans should be evicted out of the city. Second, it means that the Koreans represent a minority within a minority. More important, it implies that the Blacks are replicating the Whites' oppressive and biased practices with a less powerful group, i.e., the Koreans. The other reason behind the Blacks' rejection of the Koreans is related to economic opportunities and work labor. The latter constitutes what is called a 'cheap labor.' They accept to work in jobs which the Blacks usually decline. For example, Willie Mak, Key Chun Mak's nephew, works for "less than minimum wage," and Soomi Mak, Key Chun Mak's niece, works "like a dog."(31). Life is very expensive in New York as the BLACK CHORUS declares, and everyone in the city is trying to 'survive.' This may explain why almost all the characters from both sides are 'tired' and feeling 'sick' of everything. Grocer Mak does not have time for friends for he "Wake[s] up at five a.m., work until one a.m. Do it all over again next day. Seven days a week. Even Sunday”(p.42).

Moreover, there are more serious problems which plague the minority communities. Reverend Carter reports how innocent black children and youth fall victims to addiction, dropping out, crimes, and death because "all their lives they're ashamed, ashamed of being black....[because] racist America has stripped [them] of [their] dignity"(p.61-62).

Likewise, the Koreans' attitude towards and opinion of the Blacks is no less stereotypical and derogatory: they are 'uppity', 'niggers', 'coons', 'black devils'(p.21). Seeto “can't believe people in this day and age are still using the word, 'tar baby"'(p.21). This implies that racial profiling and prejudice is still prevalent in the American society despite this long period of living together. As a matter of fact, one should take into consideration the historical and cultural background against which the incident that triggers these racial tensions takes place.

In Kimchee and Chitlins, Wong's obvious intention is to warn against making hasty judgements. She firmly asserts that understanding and respecting each other is a must in multicultural societies like America because of its role in ensuring peace, coexistence and equality. The 'Boycott incident' is triggered when Nurse Ruth Betty fails to culturally understand the behavior of Grocer Key Chun Mak, the Korean grocer. Betty accuses Mak of disrespecting and insulting her because she has "been putting money into that Korean man's pocket for five years, and he can't even look [her] in the eye when [she] open[s] [her] purse." Another behavior which irritates Betty and aggravates the misunderstanding between the two local communities is when Mak refuses to touch her hand. She says: "Once, I held out my five dollars...and he refused to take it from my black hand. Do I look like I have a social disease"(emphasis mine)(pp.22-23). 'Black' and 'disease' clearly illustrate Betty's feelings of inferiority that is rooted in attitudes and practices that date back to the time of slavery. Mak tries to defend himself and explain the cultural differences that make him behave in this way for rather than a sign of impertinence and impudence, Mak informs the audience: "I show them plenty of respect....I don't look in their eyes. I don't touch them in false sign of friendly greeting. This is our way. The Korean way"(p.42).

Ruth Betty's stance and action, indeed, can be understood in the light of the slavery narrative. Betty has two first names because she does not have last name. she rejects that name and she will not even speak it because it was the name of her "great- great-grandmother's slave master." She says: "I don't know what my real family name is. I don't know what tribe I'm from. I don't have any family history... And you can't get or give a better reason to boycott than that"(p.78) 
It is crystal clear that Betty's feelings of inferiority subconsciously work hand in hand with cultural misunderstanding to make her treat Mak in this way. Commenting on this, Fathy avers that "The play suggests that the slave master of the past has replicated himself in Grocer Mak, but this time Ruth Betty is the strong side and this helps her take revenge from him"(2011, p.83). This opinion is consolidated by Thompson's perceptive comment on the 'Boycott' incident. He thinks that the history of racial profiling and discrimination repeats itself, but this time the white man has no role in it. He describes what has been happening as "Incredible....Amazing, just amazing," and goes on to say: "It's like the '6os all over again, but in reverse. I don't mean to sound relieved. But, I mean, this time, the white man isn't part of the lynch party. It's all so strange"(p.19). However, Thompson's is a naïve and simplistic viewpoint because in spite of the absence of the 'white man' from the scene, he is there, in the background manipulating and controlling the process of how both minorities are presented to the wider community.

Tara Sullivan, for example, decides, without consulting Seeto, to delete parts of her interviews with Asian community. This outrages the Asian chorus which considers Seeto responsible for hiding information and distorting the truth: "You traitor... You buried us like kimchee"(p.52) in contrast to the African chorus which acclaims her for, apparently, supporting and telling 'the truth' about them. Reverend Carter promises to help her by giving her the address of Matilda Duvet who claims being attacked by some Koreans. But Seeto declines his offer not because of her responsibility towards the yellow color but because of her ethical values: "You don't have me in your pocket, sir. I'm fair and impartial"(p.56).

After this incident, Seeto begins to realize the dangers of dealing with people and judging them based on their ethnicity, gender, color or any other physical or cultural marker. Another incident that pushes Seeto further in the path of self-recognition is related to her boss, Thompson, who accuses Reverend Carter of being racist. However, surprisingly enough, Seeto makes use of Carter's declaration that "A black man in America can never be a racist. To be a racist, you have to have power. And that, I most certainly do not have"(p.57). and in another situation, "people of color can't be racist. It implies power, which we don't have"(p.63)[emphasis mine]. The use of the pronoun 'we' here is significant as Seeto begins to feel that completely assimilating into the dominant white society and forsaking one's roots is wrong. She begins to sense that she belongs to another community that is often mispresented. In fact, Reverend Carter believes that Seeto has a "responsibility and an obligation to remind racist America how racist it is"(p.48). Racism is practiced through a number of regulations and policies that stand between the minorities and achieving their dreams. Ruth Betty, for example, has been asking the bank for a loan to start her own business and stop working for others for three years. But they refuse because they consider her a "bad risk" since she does not "have the proper collateral"(p.47). The Blacks do not trust White 'racist' institutions as Reverend Carter describes them; they can not trust the 'White' court to grant them their civil rights; therefore, they take their complaints to the streets.

The white institutions, however, do not work for the Koreans as well. A Korean Church Woman speaks of the same difficulties in getting loans from an American bank. Therefore, the Koreans make their own business arrangements. Businesses are kept within families. Koreans are usually lending money to other Koreans and they grant loans from a "pool of money they maintain for economic advancement." It is apparent, as this woman proclaims that "The American system does not work for Koreans either"(p.78).

Seeto's journey from self-denial to self-realization takes place towards the end of Act II when she witnessed four black kids beating a Vietnamese kid as they think he is a Korean. The yellowcolored Seeto is now face to face with the stark truth. She does not belong to the white 
community but to another one. The boys were crying loudly while beating the boy: "filthy Korean dog bastard. We're going to send you back to Korea"(p.82) while the Vietnamese desperately tried to explain that he is not.

This incident reminds Seeto of another that took place in her school days. Telling this story indicates that she can no longer live in the present state of self-denial. Seeto's classmate was a Thai who was terribly fond of tetherball. she was uncomfortable and her accent was thick. In spite of this girl's desperate attempts to befriend Seeto and hang around with her all the time, the latter does not "want to be associated with her." Seeto, however, was shocked when a substitute teacher "mistook her-ME, the all-time tetherball champion- for that horribly awkward girl"(p.82). She experiences the same feelings of shock and dissociation in the Vietnamese boy incident. She pronounces:

I was too busy, too preoccupied with disassociating myself from that squirming, weak, yellow boy on the ground. Coolly, I hid myself behind my profession thoroughly brainwashed by my complete-and-utter certainty that I could not and would not be hurt ... because I was NOT like that kid.(82)

But unfortunately for Seeto, those black boys who were beating the Vietnamese boy with their baseball bat destroyed her "beautiful delusion one and forever." For as she asks herself: "if it wasn't yellow, then what color did I think I was"(p.82).

"Who am I?" is the most essential, recurring and urgent question in Kimchee and Chitlins. From the beginning of the play, the characters engage in various attempts to define 'who they are?' in their multicultural society. Their success in defining and positioning themselves depends on a number of factors: cultural, social, political, economic, etc. As stated in the first section, Blacks and Asians are offered three main options to choose among. The first is to assimilate with the values and norms of their host society. This is very clear in Seeto and Ruth's attempts to emulate the white girls in their physical appearance. These two minority women entertain the belief that "blondes have more fun"(p.41) and, therefore, they want to be Tara-like. Seeto remembers how her mother reproached her for using the 'platform shoes' to be 'taller,' and the 'eyeliner' to make her "eyes look bigger"(p.41).

Moreover, both Soomi Mak and Ruth Betty show much sensitivity towards how their hair should look like. Soomi remembers a classmate of her, Stacy Skowronski, when she was in the girls' room combing her long blonde hair which was like 'gold'. She is obviously envious of her classmate. Ruth Betty agrees with her. She admires the straight hair-something she lacks- and says: "All the boys flocked around the girls with straight hair"(p.42). Betty remembers also when she once was in a House of Beauty and looked at the magazines and saw "All those perky noses and blue eyes"(p.42).

It is clear that there is a deep-seated feeling of inferiority in the case of these three girls. The dominant white culture sets for them unattainable ideal of beauty which deprives them of the will to cherish their natural physical features. They believe that 'blonde girls' have better chances in terms of social acceptability and finding partners.

Willie Mak tells his own version of the assimilation story. He says that when he was back in Korea, he "learned about the melting pot," and he wanted to "melt into the melting pot....[and] get along with everybody"(p.67). He remembered the "crying faces of happiness" when they were in "the courtroom to make the pledge of allegiance." They were all so different, but they were happy. 
But now the situation is changed. He is carrying a gun and is ready to use it to protect himself and his interests.

The second group members are anti-assimilationists. They refuse to succumb to the values and standards defined by the White society. Seeto's mother is a case in point. She throws away all the instruments of assimilation-which mainly pertain to her daughter's outward physical appearanceand she keeps questioning their use and role in helping her daughter in her life.

The same opinion is pronounced by Soomi Mak who wants to shout "I am here" according to Willie Mak and tells Seeto about the Church that "organized classes for the Korean businessmen to get along with the American people"(p.74). But some Koreans do not want to go to such classes and reasonably ask about the reason that prevents people from taking classes to get along with them, i.e., the Koreans. Soomi Mak plausibly wonders: "Why don't people take classes to learn about Korean culture? I say, "let 'em eat kimchee." If Uncle Makie doesn't want to go, right on!"(p.74). This means that the process of assimilation should not be one-sided. All communities in a multicultural society should engage in this process to assure succeeding in living peacefully.

The reference to Kimchee leads us to the third group who tries to negotiate a third path or a new identity that strikes a balance between one's past and roots and one's new environment. This is indicated in the first part of the play title: Kimchee and Chitlins. Trying to elucidate her approach, Wong, earlier in the play and in a conversation with Seeto, lets Thompson say: "Food is a serious subject. Have you noticed that every major relationship you have or ever will have...was and is solidified, destroyed, or reconfigured at the dinner table"(p.9). Again, stereotypical images prevail as there are many references in the first few pages to 'chopsticks' being the main means of eating among Asians in contrast to 'spoon and fork' among the whites. The implication of Thompson's statement is that the minorities should recognize that they have many things in common. There are more to unite them and help them to overcome difficulties than separate them. These two traditional dishes are part of the Korean and African culture and heritage. Grocer Mak, for example proclaims that Kimchee is not just "dead cabbage," it is the 'heart of Korea' because when he eats it, his "homesickness says 'Adios'”(p.25). By offering the African Barber Brown some kimchee to help cure his sinuses problem, Mak strengthens the possibility of mutual understanding. When Brown realizes that eating Kimchee is not enough and that he should combine it with a dish of his own, Chitlins, he finds out that it is very tasty and effective in curing him. Barber tells Mak:

I was eating your Kimchee. I was sneezing my head off. Then for no reason, I put some of that kimchee into my chitlins, and...it tasted good. AND it cleared up my sinuses. So, I got to thinking....Kimchee and Chitlins. The wonder food or the wonder drug.(p.25)

The implication here is quite clear: if each group tries to forget their biases and understand each other, coexistence and mutual trust and respect are quite possible.

There is another factor that should be considered when dealing with the question of coexistence, the economic factor. Although a minor character, Barber Brown's attitude towards the boycotting incident illustrates this. He is compelled to stand with his community against the Koreans although his business has been negatively affected by the boycott since a considerable number of his 'customers' are Koreans. He is "losing money being out on the picket line"(p.26).

\section{Conclusion: 'We Shall Overcome'}


Wong's semi-autobiographical Kimchee and Chitlins is a clear and poignant exploration of the economic hardships and cultural misunderstanding minorities in general and Korean/African in particular experience in the multicultural American society. Obviously, Wong is not in preference of the 'melting pot' approach to living in America. Instead she advocates the 'Salad Bowl' approach that guarantees the respect of the cultural, social and religious heritage of each minority. This may account for the promulgation of the motto 'YELLOW IS BEAUTIFUL' which is reminiscent of the motto of the Black Cultural Movement in the 196os; 'BLACK IS BEAUTIFUL'. She also goes against treating Asians and blacks collectively as there are many differences among the Koreans, Japanese, Thai, Chinese, etc., and the same applies to the blacks. She believes that this will enable people to overcome hardships and difficulties.

At the beginning of the play, Seeto avows that her goal, as a correspondent for and journalist, is to "make a difference. To ensure fairness and civility in the world"(p.34). But she soon finds out this is difficult because of power imbalance among the various groups that set up American society. The White, as the play adumbrates, are in control of the process of 'representation'. For reasons other than presenting news and stories objectively, they suppress, select, and circulate materials that serve their purposes. Seeto implicitly accuses many news channels of "laundering and bleaching the news"(p.63). This policy contributes to keeping them under/misrepresented. The Koreans feel distraught when part of their interviews and stories were suppressed in favor of the black. They keep repeating: "What about our dreams? What about our side of the story"(p.48). The message here is that dreams of all minorities should be respected and cherished. More important, Seeto does not want to be part of the 'hate machine'. She does not want to "inflame people" although the case is "inflammatory by nature"(p.63). Therefore, she is not going to sanitize the news but to be partial and tell the truth as it is.

Wong, in fact, was displeased with the American mainstream media's stereotyping treatment of often racially marked members of minorities that are consistently exoticized, pathologized, or criminalized. Accordingly, Kimchee and Chitlins exemplifies a "move towards a more expansive understanding of Asian American identity in Asian American theatre"(Zeng, 2015,p.25).

Wong, furthermore, speaks of the possibility of reconciliation between the two conflicting sides. Although the first meeting between them degenerates into fist fighting and pot shooting, members of both sides agree that "this get-together is good. Talk is good. [And] give hope for a solution"(p.75). A symbolic solution is offered by barber Brown and Grocer Mak. When Mak offers his shop for sale, Brown approaches him and reminds him of his early days in the shop. He believes that they can resist and coexist if theyare united: "United we stand." All agree with him. The play ends with Brown taking down the 'For Sale' post and expressing his wish to visit Mak's house and have dinner with him. It is obvious that Mak-Baraber relationship transcends the limits of business transactions to evolve into a cross-cultural and cross-racial relationship based on a desire to appreciate and understand each other. As Mayaram argues that rather than a mere site of "prejudice, conflict, and exclusion," the city where the two minorities live is also a place of "cohabitation and conflictual coexistence, where difference is encountered and confronted, hate speech articulated but also negotiated"(qtd. In Zeng, 2015, p.23).

\section{Bibliography}


Berner, H. (2003). "Home Is Where the Heart Is? Identity and Belonging in Asian American Literature." Unpublished Ph.D. The Ruhr-University Bochum

Erler, C. "The Obama Code: Ghosts and Monsters in the Visual Data Sphere." CTheory 17 Dec. 2010 $<$ http://www.ctheory.net/articles.aspx?id=622>.

Chin, F . (1991). Come all ye Asian American writers of the real and the fake. In Chan, J. P. and et al.,eds. The big Aiiieeeee! : And anthology of Asian-American literature. New York: A Meridian Book. 1-92.

Coleman, S. R. (2003). "Dashiki Theatre Project: Black Identity and Beyond." Diss. of Loiusiana State.

Elisabeth H. (2003). "Faces of Discrimination: The Case of Sex Equality": pp.5-13. in Janet Cormack," Protection against discrimination and gender equality: How to meet both requirements", The Austrian Ombud for equal employment opportunities, Ministry for health and women.

http://homepage.univie.ac.at/ holzleez/CormackProtection.pdf

Fathy, M. (2011). Asian American Ethnicity in American Drama: A Study of Philip Kan Gotanda's Yankee Dawg You Die (1987), and Elizabeth Wong's Kimchee and Chitlins (1990). Assiut: Assiut University Press.

Feagin, J. R. and Melvin P. S.(1994). Living with Racism: The Black Middle-Class Experience. Boston: Beacon Press.

Ferguson, R. et. Al.(eds.). (1990). Out There: Marginalization and Contemporary Cultures. New York: The New Museum of Contemporary Art.

Fugazza, M.(2003). "Racial Discrimination: Theories, facts and Policy." International Labor Review 142.4: 507-528.

The Journey from Gold Mountain: The Asian American Experience.

https://jacl.org/wordpress/wp-content/uploads/.../2006_GoldMountain_CurGuide.pdf

Kim. J. Y. (2010). "The difference a smile can make: interracial conflict and cross-racial performance in "Kimchee and Chitlins" Url=http://citeweb.info/20102700743 | doi=10.1353/mdr.2010.0019 | author=Ju Yon Kim\}\}

Lee, J. F. J.(2000). "Preface": Asian American Actors: Oral Histories from Stage Screen and Television. Jefferson, NC: McFarland. 1- 2.

Heldke, L. \& Peg O’Connor. (2004). Oppression, Privilege, \& Resistance. Boston: McGraw Hill .

Olson. B. (2003). Attitudes towards Multiculturalism and Cultural Diversity: The Effects of Multicultural Training. University of Wisconsin -Stout.

Omi, M. and Howard Winant. (1986). Racial Formation in the United States. From the 196os to the 1980s New York: Routledge.

Racism against African-Americans" http:www.articles.com/racism-against-african-americans.html.

Song, S. (2017). "Multiculturalism", The Stanford Encyclopedia of Philosophy, Edward N. Zalta (ed.), URL = $<$ https://plato.stanford.edu/archives/spr2017/entries/multiculturalism/>.

Sue, Derald Wing. (2003). Overcoming our Racism: The Journey to Liberation. San Francisco: Jossey-Bass.

Wong, E.(1994). Kimchee and Chitlins: A Serious Comedy about Getting Along. Illinois: The Dramatic Publishing company.

Zeng, Minhao. (2015). Performing Racial Cosmopolitanism: Contemporary Asian American Theatre. A Dissertation. USA: University of Alberta. 